\section{UM NOVO PLANEJAMENTO PARA UM NOVO BRASIL?}

\author{
Ester Limonad e Edna Castro (Org.) \\ Rio de Janeiro: Letra Capital; ANPUR, 2014.
}

Cibele Saliba Rizek

Universidade de São Paulo, Instituto de Arquitetura e Urbanismo, São Carlos, SP, Brasil

Alguns momentos históricos parecem cruzar dimensóes e acontecimentos que irrompem dentro do fluxo de temporalidades aparentemente aplainadas para constituir feixes de significações e/ ou inflexôes que ganham visibilidade, conferindo densidade para eventos passados e, por vezes, anunciando possibilidades. Julho de 2013 parece ser um desses momentos, não só porque era impossível não discutir os acontecimentos das chamadas "jornadas de junho", mas também porque o simpósio organizado pela Associação Nacional de Pós-Graduação e Pesquisa em Planejamento Urbano e Regional (ANPUR), nos momentos finais de uma gestão que se iniciara com a posse e, em seguida, a morte de Ana Clara Torres Ribeiro, traria a marca de suas três décadas de existência.

O livro Um novo planejamento para um novo Brasil? resultou de um simpósio ocorrido durante a reuniáo da Sociedade Brasileira para o Progresso da Ciência (SBPC) em julho de 2013, cujo tema foi Ciência para um Novo Brasil, realizado na Universidade Federal de Pernambuco. O tema escolhido para a reuniáo da SBPC inspirou o título do simpósio da ANPUR, cujos resultados foram reunidos nessa publicação, inspirada pelo calor dos acontecimentos, em sua confluência com a promessa de um "novo" país: uma economia mais vigorosa; uma trama territorial claramente urbana; novos patamares democráticos, que comportavam grandes manifestaçóes de massa; uma discussão a respeito de um horizonte de desenvolvimento; sinais de estabilidade institucional. Já em sua capa, a partir dos dizeres de alguns cartazes que marcaram as manifestaçóes de 2013, comparece o que seria, desde aquele momento, denominado como a voz das ruas: "se a tarifa não baixar a cidade vai parar"; "desculpe o transtorno - estamos mudando o país"; "é tanto problema que náo cabe em um cartaz”. Talvez se possa dizer que essa densidade de questóes comparece e define o livro e o simpósio que lhe deu origem, com textos que apontam desde uma discussão teórica densa até debates que cobrem um conjunto de elementos que caracterizam, nacional ou regionalmente, o Brasil das primeiras décadas do século XXI e sua natureza urbana.

$\mathrm{Na}$ primeira parte - "Reflexões críticas e perspectivas possíveis: Estado, planejamento e as revoltas populares" -, Ana Fani Alessandri Carlos, Rainer Randolph, Carlos Antônio Brandão, Ester Limonad e Edna Castro discutem as manifestaçôes de 2013 e aquilo que era possível vislumbrar a partir de sua força e de seu caráter, até certo ponto, surpreendente e inovador. Qual seu conteúdo de classe? Como definir suas dimensões políticas? Afinal, qual novidade se avizinhava? Qual novidade era desejável, diante do quadro de crise e agravamento das condiçóes de vida urbana? Quais transformações eram possíveis no âmbito da produção nas margens do Estado, como aponta Castro, utilizando o vocabulário de interpretação de Veena Das e Deborah Poole?

Talvez dois anos depois desse debate, diante do novo quadro que vem marcando as manifestações de 2015, caiba apontar algumas das inquietaçóes e questóes presentes em meio aos textos e suas ênfases. Afinal, são essas questôes que parecem continuar como uma espécie de motor contínuo na reflexão brasileira sobre a cidade, sobre os processos de metropolização, sobre um urbano que se espraia, colonizando e assimilando seus outros. Visitar e mapear algumas dessas inquietaçóes pode ser, entáo, a melhor maneira de apontar a atualidade do texto e das discussóes que nele têm lugar.

A primeira dessas inquietaçóes desenha uma crise urbana de grande espectro. Essa crise urbana seria, ao mesmo tempo, como aponta Carlos, uma crise teórica, já que, referindo-se a Daniel Bensaïd, a autora aponta a necessidade de recompor os vínculos entre teoria e prática (p. 28). No coração dessa crise, como possibilidade de entrever sua superação, seria necessário revelar contradiçóes, criticar a ação do Estado, desvendando sua lógica e suas imbricaçóes com a acumulação do capital em suas formas e 
modulações contemporâneas, indicar a impossibilidade de resolução das questôes social e urbana por meio de políticas públicas, à luz da recusa crítica do existente, capaz de permitir um salto para além “da dimensão ideológica do conhecimento" (p. 29). A homogeneização e fragmentação dos lugares da cidade, indelevelmente constituída pela propriedade privada e pela forma mercadoria, a imposição do homogêneo, o esvaziamento dos espaços de sociabilidade póem os impasses entre uma teoria destituída da prática e uma prática destituída da teoria (p. 35). Essa crítica radical tem ainda como alvo uma suposiçáo de forte conteúdo ideologizante. Os argumentos do texto se contrapóem à presença de um caráter civilizador associado ao modo capitalista de produção, enfatizando, sobretudo, que o capitalismo contemporâneo, em seu momento financeirizado, encolhe, quando não destitui direitos sociais, entre os quais o direito à cidade, que os movimentos de junho de 2013 pareciam reivindicar.

É também sobre a prática ou a práxis que o texto de Rainer Randolph se debruça. Novamente, um conjunto de temas, perguntas e questôes sobre a insurreição - as possibilidades das zonas insurgentes e seu deslizamento crítico para a subversão no âmbito das dimensóes espaciais, somadas à potencialidade dos espaços subterrâneos de resistência delineia o que o autor denomina de meta-planejamento. Seu delineamento guardaria a possibilidade de subversão das relaçôes entre planejadores e população envolvida, abrindo a possibilidade de perceber e potencializar as energias utópicas que pulsam nesses lugares recônditos, localizados abaixo das camadas mais visíveis de deterioração das condiçôes urbanas e das condiçôes de vida. Promessa e redenção se assentariam, então, na potência do deslizamento da insurgência à subversão.

O texto de Brandão traz no título a palavra desafio. Seu objeto de discussão são os desafios teóricos e analíticos: trata-se de recolocar como centro das questôes teóricas as relaçôes entre as classes e o espaço urbano regional. A identificação dos "agentes cruciais", dos sujeitos, das classes e suas alianças e coalizóes aponta para a necessidade de uma Economia Política do desenvolvimento socioespacial desigual ou mesmo de uma economia política da geografia, cujo objeto seria constituído pelo desenvolvimento desigual do processo de acumulação do capital (p. 61). Diante da falta e das lacunas dessas conformações teóricas e analíticas, Brandão aponta ainda a necessidade de perceber e desvendar a transformação do espaço nacional em "base operativa e plataforma de simples circulação de capitais usurários e lócus de valorização dos grandes capitais ancorados na predação e degradação humana e ambiental” (p. 66). Nessas condiçôes, "a cidade mesma se torna um negócio e há uma 'privatização' do planejamento urbano” (p.71). Classes, divisão do trabalho, Estado, espaço e grande capital conformariam, então, um nó central do debate em busca de requalificação, a partir de um arcabouço contra-hegemônico que permitiria entrever uma nova produção social e política do espaço (p.78).

Os dois textos que finalizam a primeira parte do livro são de suas organizadoras, não por acaso duas presidentes da ANPUR: Ester Limonad e Edna Castro. A pergunta de Limonad - "novo planejamento ou novo Estado para o Brasil?” - náo poderia ser nem mais pertinente, nem mais contemporânea. A autora indica, entre muitos outros elementos, "a interescalaridade da lógica territorial do Estado e da lógica da acumulação, entrelaçadas historicamente, e a transescalaridade dos fluxos que se materializam através da financeirização do espaço social contemporâneo" (p. 88). As opacidades de todo esse processo, o caráter ilusório das formas de participação institucionalizada, a ruptura entre o "social" e o "político", a fragilidade intelectual e dos intelectuais, isto é, a fragilidade de seu comprometimento com a transformação social, demonstram que "estamos a buscar saídas ou formas de avançar em um jogo que se assemelha cada vez mais a um jogo de cartas marcadas onde $[s i c]$ o oponente, além de dar as cartas, estabelece as regras do jogo, que mudam casuisticamente conforme os interesses hegemônicos [...]" (p. 97).

Castro, por sua vez, mobilizando um referencial teórico que se assenta em Veena Das e Deborah Poole ${ }^{1}$ para pensar as margens do Estado, também problematiza os limites da interpretação e a tensão

1 Ver: DAS, Veena; POOLE, Deborah (Ed.). Anthropology in the Margins of the State. Santa Fe: School of American Research Press; James Currey, 2004. Ver também: DAS, Veena. Fronteiras, violência e o trabalho do tempo: alguns temas wittgensteinianos. Revista Brasileira de Ciências Sociais, v. 14, n. 40, p. 31-42, jun. 1999. 
entre teoria e empiria, fartamente atualizada pelo caráter múltiplo e um tanto inédito dos movimentos de junho de 2013. A questão, a partir dessas referências, afirma a autora, é "o lugar de onde procuramos compreender o que de fato é o Estado, ou melhor, uma etnografia sobre as práticas sociais, os lugares e as linguagens que conformam os lugares nas margens do Estado-Nação" (p. 103). Utilizando o repertório das ciências sociais e da sociologia contemporânea, em particular, o artigo busca analisar as mobilizaçóes insurgentes e a potencialidade de conflitos que ganharam a cena pública em 2013: aos movimentos de junho, somaram-se as mobilizaçôes em torno das intervençôes vinculadas à Copa do Mundo e seus custos, passíveis de serem mensurados em lágrimas e sofrimento (como sugeriria Veena Das). Castro ainda tece um quadro de análise desses eventos a partir de uma reflexão ancorada nos chamados estudos pós-coloniais, na perspectiva de desconstrução de imagens, representaçôes e crenças que não questionam os parâmetros impostos pelas raízes fincadas pela colonização. Para além de uma suposta uniformidade, a autora aponta o que pulsa no "sentimento do brasileiro diante de uma ordem política, social e jurídica que [...] [o] fragiliza, invisibiliza, subtrai da existência como cidadãos de direito e sujeitos capazes de pensar sobre seus desejos, seus direitos e sua existência” (p. 117).

A segunda parte do livro dedica-se à reflexão dos espaços metropolitanos, das desigualdades e mobilidade urbana. $\mathrm{O}$ artigo de Jeroen Klink póe a questão da governança (ainda que necessariamente de ponta-cabeça) e o tema, inescapável, do Estado desenvolvimentista ao longo da história brasileira. $\mathrm{Na}$ conclusão do artigo, o autor aponta os desafios da articulação de escalas, circuitos econômicos, discursos e práticas espaciais contra-hegemônicos, assim como uma herança tecnoburocrática que teria profissionalizado o planejamento participativo, distanciando os movimentos sociais e "dissociando o debate sobre o planejamento das discussóes mais amplas sobre poder, conflitos e representações hege- mônicas sobre o espaço urbano-metropolitano" (p. 144). De outro lado, um projeto alternativo "preencheria” a governança metropolitana com outras representações, imaginários e horizontes de emancipação social, questionando relaçôes naturalizadas entre Estado, sociedade e cidades num mundo globalizado e mercantilizado.

Outros temas e questôes ainda compóem essa coletânea: a dimensão regional apresentada por Hipólita Siqueira, que destaca as desigualdades entre as regiōes e o pacto federativo; o debate federativo e o caráter metropolitano da jovem capital brasileira, no artigo de Benny Schvarsberg; as questôes de mobilidade urbana no âmbito metropolitano; a tensão entre fragmentaçáo e integração nas metrópoles brasileiras; o tema do planejamento e suas relaçóes com a dimensão participativa por meio das questóes de Belo Horizonte, sistematizadas por Jupira Gomes de Mendonça, no âmbito metropolitano; por meio da discussão de Olinda, a perspectiva da conservação integrada e do que os autores Virgínia Pontual e Silvio Zanchetti identificaram como planejamento culturalmente orientado; os elementos e dimensóes da questão ambiental urbana, pela ótica de Maria Lucia Refinetti Martins; e, finalmente, as "cidades da floresta" pela ótica de Saint-Clair Cordeiro da Trindade Jr. Os vários artigos desse livro desenham as questôes de um Brasil urbano, em suas determinaçôes e tensōes com o planejamento, a participaçáo, o Estado, as relaçóes de classe, as desigualdades e as dimensóes teóricas e políticas que se articulam em cada prisma, em cada elemento. No enovelamento e nas articulaçôes, nas esquinas das cidades e no cruzamento dos textos, o leitor entrevê a necessidade e a urgência de ir além do que está dado, de desvendar e revelar as urdiduras que constituem o Brasil e o urbano do século XXI. Esse era o lugar que, naquele momento, o simpósio e seus resultados buscaram ocupar.

Cibele Saliba Rizek: cibelesr@uol.com.br. 